\title{
Influence of Chinese and Western Culture on Modern Church Architecture in Yan'an Area
}

\author{
Li Wang, Yongjian Qu \\ College of Landscape Architecture and Arts, Northwest A \& F University, Yangling, China \\ Email: superwli@126.com
}

Received 6 November 2015; accepted 29 November 2015; published 2 December 2015

Copyright (C) 2015 by authors and Scientific Research Publishing Inc.

This work is licensed under the Creative Commons Attribution International License (CC BY). http://creativecommons.org/licenses/by/4.0/

c) (i) Open Access

\begin{abstract}
Based on the historical records and field investigation, this paper aims at elaborating the architectural styles, interior space design and architectural landscape of modern church architecture in Yan'an, analyzing the influence of Chinese and western culture on modern church architecture in Yan'an and expounding the historical and cultural value as church architecture, which will play a great role in the protection, inheritance and utilization of modern architecture in Yan'an area.
\end{abstract}

\section{Keywords}

\section{Modern Church Architecture, Yan'an Area, Influence of Chinese and Western Culture}

\section{Introduction}

Christianity became widely spread in mainland of China after the Opium war. As the center of Shannxi province, Christian culture inevitably exerts a profound impact on Yan'an area. Situated in Northern Shannxi province on the Loess Plateau, Yan'an area is in eastern Lvliang area of Shanxi province, western Qingyang area of Gansu province, northern Yulin area and southern Tongchuan area in Shannxi province, forming a relatively isolated geographical location. Yan'an area includes twelve counties and one city respectively: the city of Yan'an, Yanchuang, Yanchuan, Zichang, Ansai, Zhidan, Zhidan, Wuqi, Ganquan, Yichuan, Fuxian, Luochuan, Huanglong, and Huangling. Yan'an area, which overlooks the middle reaches of the Yellow River, the cradle of Chinese civilization, possesses its special Loess Plateau culture.

After a long time of collision and fusion of local Loess Plateau culture and Christianity of western culture, a new class of religious architecture, called church architecture, is created in Yan'an area. In this paper, we will adopt the literature analysis method and case analysis to collect the information of church architecture and investigate the representative church in Yan'an area, recording the architectural styles, interior space design and architectural landscape of modern church architecture in Yan'an area. The research of church architecture in 
Yan'an area not only has special evaluation on the propagation of western culture and the promotion of the blend of Chinese and western culture, but also makes up for blanks of church architecture in remote areas.

\section{The Situation of Christianity in Shannxi}

In Chinese history, there are four missions about the spread of Christian. In the fourth mission, the western countries opened the gateway of China with their military power after the Opium War. This mission also opened the Chinese modern history prologue, causing the collision and fusion of Chinese and western culture.

\subsection{Background of Christianity in Shannxi}

The Christian first came into Shannxi province at the end of Ming Dynasty. After the Opium War, a large number of Christian congregations came into mainland of china. Meanwhile, the Christian in Shannxi province got great development. Under the great effort of preachers, the Christian got widely spread in the relative self-containment Yan'an area. The Christian church was first established in Fuxian at the early of Qing Dynasty. There are two Christian churches in Dong village and Beidaode village which are the earliest Christian churches recorded in the Yan'an history [1]. In 1844, the Christian pastoral area of Shannxi province is established. In 1877, the parish of northern of Shannxi province is build. In 1911, the parish of northern of Shannxi province is divided into parish of Yan'an area which is up graded into pastoral area of Yan'an area in 1924 [2]. It can be seen that as the widely and deeply development of Christian church in Yan'an area, the power of Christian church became larger.

The Protestant first came into Huangling County in Yan'an area in 1901. In 1910, a Protestant church was built by a Swedish priest in Yichuan County which was destroyed by the Japanese airplane in 1940. This is the earliest Protestant church in history record in Yan'an area.

From the above discussion, the widest spread religious in Yan'an area is the Christian and then Protestant. And there is no record about the Orthodox in local history record. There are no records of Christian spread in Zhidan and Wuqi counties. The Wuqi County is the end of the long march of the Red army and Zhidan County is the earliest Soviet area in Northwest of China. It can be inferred that the no records about the spread of Christian in these two counties is related to not-much history record of these two counties.

The missionary of Christian use their memory and old drawing to build Christian church by employing local workers. The Christian church in Yan'an area became an exotic landscape which has totally different architecture style compared to local vernacular architecture.

\subsection{The Spatial Distribution of the Christian}

The church is a place where the Christian can do worship and meeting. Because of the common belief and evaluation system, the church developed as a location for spreading their doctrine and power. Therefore, the spatial distribution characteristics of the Christian culture propagation can be analyzed by the spatial-time variation.

We first summarize the local history record of Yan'an area and checked the quantity and location of the Christian church during 1840-1849. Based on this investigation, we take field investigation and measurement of the church in significant areas. Finally, we get the conclusion that there are totally 23 churches in the modern Yan'an areas, where the Christian church number is 12 and the Protestant church is 11, respectively.

From Table 1, it can be seen the difference between the temporal and spatial distribution of Christian church in Yan'an area. First, there are 6 churches located at the southern of Yan'an area, including Fuxian, Huanglong and Luochuan. Among them, only one church is in the town while five of them are located in the village. Second, there are 3 churches located at the northern of Yan'an area, including Zichang and Ansai. Among them, only one church is in the village while two of them are located in the downtown. Finally, there are 3 churches located at other area in Yan'an area, including Huangling, Yan'an and Yanchang. Among them, only one church is in the village while two of them are located in the downtown.

From the above discussion, it can be seen that the distribution characteristics of the Christian church has the trends from the boarder of southern and northern of Yan'an area to the center of this area. As the development, the church power has diffused to the center of Yan'an area which can be called from the village to county and town.

From Table 2, it can be seen the difference between the temporal and spatial distribution of protestant church 
Table 1. The distribution of Christian church in Yan'an area.

\begin{tabular}{|c|c|c|c|c|c|c|}
\hline \multirow{2}{*}{ Name } & \multirow{2}{*}{ Christian church } & \multirow{2}{*}{ Time } & \multicolumn{3}{|c|}{ Location } & \multirow{2}{*}{ Summation } \\
\hline & & & County & Town & Village & \\
\hline \multirow{2}{*}{ Fuxian } & Chuankou village & Tongzhi period [3] & & & 1 & \multirow{2}{*}{2} \\
\hline & Dong village & Early in Qing Dynasty & & & 1 & \\
\hline \multirow{2}{*}{ Huanglong } & Shendi village & Unknown & & & 1 & \multirow{2}{*}{2} \\
\hline & Taipingliang village & Unknown & & & 1 & \\
\hline \multirow{2}{*}{ Luochuan } & Wangjiaxiang & 1922 & 1 & & & \multirow{2}{*}{2} \\
\hline & Pengjiahe & Unknown & & & 1 & \\
\hline \multirow{2}{*}{ Zichang } & Wayaobao & 1928 & 1 & & & \multirow{2}{*}{2} \\
\hline & Wujiaping & 1931 & & & 1 & \\
\hline Ansai & Xinlezhai & 1924 & 1 & & & 1 \\
\hline Huangling & Pingtian village & 1925 & & & 1 & 1 \\
\hline Yan'an & Qiaoergou & 1931 & & 1 & & 1 \\
\hline Yanchang & Ganguyi & 1931 & & 1 & & 1 \\
\hline Summation & & & 3 & 2 & 7 & 12 \\
\hline
\end{tabular}

Table 2. The protestant church distribution of Yan'an area.

\begin{tabular}{|c|c|c|c|c|c|c|}
\hline \multirow{2}{*}{ Name } & \multirow{2}{*}{ Protestant church } & \multirow{2}{*}{ Time } & \multicolumn{3}{|c|}{ Location } & \multirow{2}{*}{ Summation } \\
\hline & & & Town & County & Village & \\
\hline \multirow{3}{*}{ Yichuan } & West street in downtown & 1910 & 1 & & & \multirow{3}{*}{3} \\
\hline & Jiyi town & Unknown & & 1 & & \\
\hline & Gaojiawan & Unknown & & 1 & & \\
\hline \multirow{2}{*}{ Yanchuan } & Yongping town & End period of Qing Dynasty & & 1 & & \multirow{2}{*}{2} \\
\hline & Yanshuiguan & End period of Qing Dynasty & & 1 & & \\
\hline \multirow{2}{*}{ Yanchang } & Lichangsan reiver & 1920 & & 1 & & \multirow{2}{*}{2} \\
\hline & Downtown & 1922 & 1 & & & \\
\hline Fuxian & Downtown & End period of Qing Dynasty & 1 & & & 1 \\
\hline Luochuan & Downtown & 1913 & 1 & & & 1 \\
\hline Huangling & Downtown & 1923 & 1 & & & 1 \\
\hline Yanan city & Downtown & 1931 & 1 & & & 1 \\
\hline Summation & & & 6 & 5 & 0 & 11 \\
\hline
\end{tabular}

in Yan'an area. First, there are 7 churches located at the eastern of Yan'an area, including Yichuan, Yanchuan and Yanchang. Among them, only 5 churches are in the town while two of them are located in the counties. Second, there are 3 churches located at the southern of Yan'an area, including Fuxian, Luochuan and Huangling. All of them are located in the downtown. And only one church located at the Yan'an city.

From the above discussion, it can be seen that the distribution characteristics of the Protestant church has the trends from the boarder of southern and eastern of Yan'an area to the center of this area. As the development, the church power has diffused to the center of Yan'an area. 


\subsection{The Propagation of Christian Culture}

The Yan'an area is located at the northern of Shannxi province which belongs to a multilevel ecological transition zone. From the Table 3, it can be seen that the transition and fusion of region characteristics has formed a broad, deep and rough culture in Yan'an area.

After the Christian came into Yan'an area, Yan'an area experienced culture collision under the strong impact of western culture. In order to avoid direct confrontation with local traditional culture collision, the missionaries first selected the southern of Yan'an area to spread Christian. In this intersection area, near the center of Shannxi province, eastern of Shanxi province and southern to Yulin area, the traditional religious belief is relative weak. The continuous western culture diffusion force Yan'an area to break through relative closed and conservative situation. Furthermore, the western church even established in the middle of the traditional downtown.

\section{Influence of Chinese and Western Culture on Modern Church Architecture in Yan'an Area}

Under the influence of Chinese and western culture, the explanation of modern church architecture in Yan'an can be described from the perspective of architectural styles, interior space design and architectural landscape.

\subsection{Architectural Styles}

In Europe, church is a Christian sanctuary where the religious Christian can gather together. Since the church's first outcome, it is the integration of the highest level of the day of architecture, architectural technology, structure, material, construction and the architecture decoration [4]. It can be seen that the church architecture is on the behalf of the highest level of western construction technology and artistic value. The Christian church, reserved today in Yan'an area, has followed the western facade composition of Rome and Gothic architectural style in its elevation. The belfry tower, beautifully carved rose windows, colorful stained glass and a large number of decoration formed the church architecture which mainly formed in the western architecture composition and vernacular architecture style in local and details. This architecture has a sharp contrast style compared with the vernacular architecture in Yan'an area.

\subsubsection{Rome Architecture Style}

The Qiaoergou Christian church is located at 5 km northwest to the Yan'an city. In 1924, Yixinghua, a Spanish missionary, purchase the site and build the church and then began to build in 1931 and finished in 1934. Now this church is an indoor training area of Yan'an Luxun Art College.

As shown in Figure 1, the Qiao'ergou church is north-face and has the plane of Brazil type rectangular. It has masonry structure with 36.28 meters long from north to south and 15.86 meters width from east to west. The entrance is on the south of the church and there is a sing hall on the entrance. The internal space is divided into the hall and the aisles. There are six polygonal columns to support the arch top of the hall. The light is come through by the side aisle window and not by the office of the side wall of side window. The interior lighting is dark and mystery. The north of the hall is the chancel which is 0.72 meter high than the ground. There are steps on both side of the chancel. The hall and aisles are beam rib architecture structure.

As shown in Figure 2, the facade of the church has three segments: the center hall and two towers on both sides. The center hall is 11.04 meters high. The first floor is a door with three concentric circular arches of coupons. And the second floor is a three continuous arch of the long narrow windows. These windows have been engraved with the catholic banner and curved with gabled sides which can highlight the center of the hall.

Table 3. The environment characteristic in Yan'an area.

\begin{tabular}{cc} 
Region environment & Characteristic \\
\hline $\begin{array}{c}\text { Geomorphic feature } \\
\text { Climate feature } \\
\text { Vegetation distribution } \\
\text { Production type } \\
\text { Regional culture }\end{array}$ & $\begin{array}{c}\text { Typical loess gully and gully area of Loess plateau } \\
\text { Eastern monsoon region and transition of inland arid area } \\
\text { Forest and transition of shrub steppe } \\
\text { Agriculture } \\
\text { The Yellow river culture, the culture of Huang Di Loess culture }\end{array}$ \\
\hline
\end{tabular}




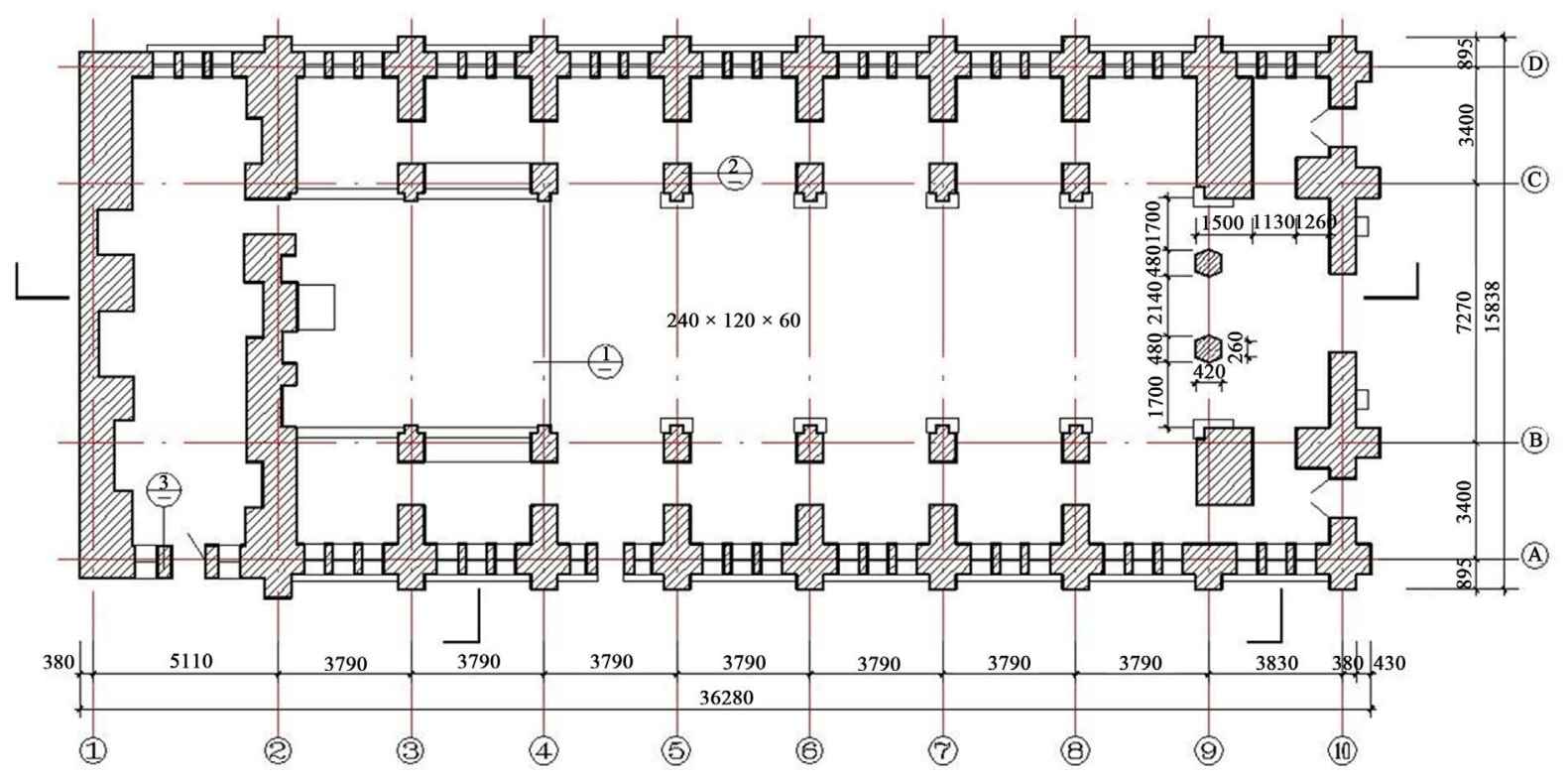

Figure 1. The plane of the Qiao'ergou church.

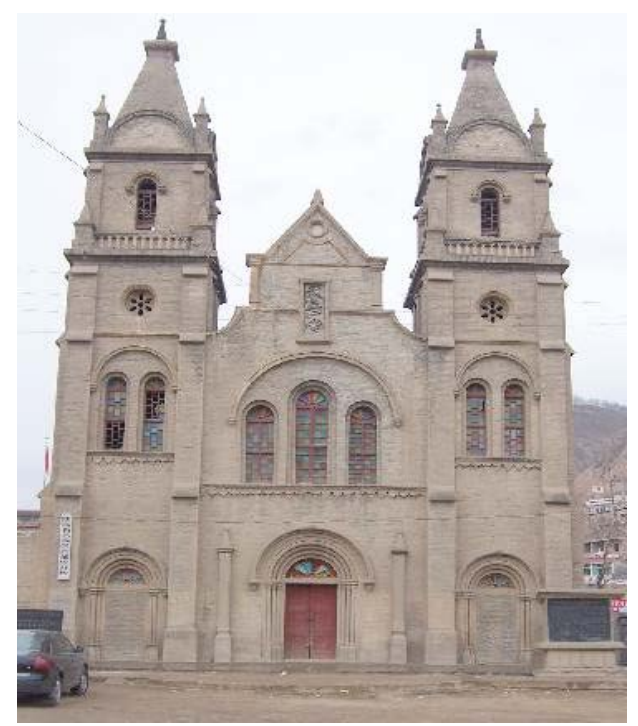

Figure 2. The south facade of the church.

The two towers on both side of the hall use the three stage structure. The first floor has three concentric circular arch form small coupons door. The second floor has two consecutive long narrow windows. There is a tracery window which is similar to a round brick rose on the wall. The third floor is the arch window. As shown in Figure 3, the tower of the church is 22.6 meters high with a 6.1 meters high pinnacle part with four pyramids. The cornice is arc and divides carefully. There are a large number of small spire tower on the roof.

In Figure 3, the interior of the church column and altarpieces use lotus, plum, orchid, bamboo, chrysanthemum, crane and so on Chinese traditional patterns. The elevation detail uses the local brick decorative patterns in Yan'an areas.

The wall of the Qiao'ergou church is large and thick but with narrow window. This structure creates a dark mystery atmosphere. The simple hall and ornate altar formed a strong contrast. The church uses the Rome style carefully and combined the heavy structure with vertical movement. Because of abundant use different form of column and coupon decoration, the church achieves a stocky, balance, strength and heavy full, the integrity of the aesthetic effect [5]. 


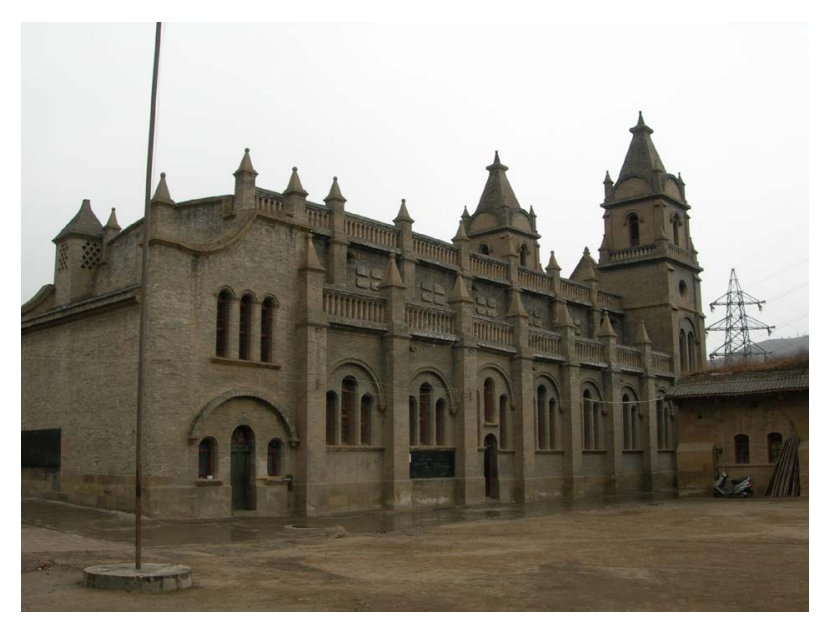

Figure 3. The west facade of the church.

\subsubsection{Gothic Architecture Style}

The Ganguyi church is located in Baota district Gangu town in Yan'an area. In 1924, a Spanish missionary purchase the site and build the church beginning at 1931 and finishing in 1934 by 300 workers. The interior of the church is destroyed during the Cultural Revolution period in China. Now this church is a food grain storage house of Gangu station.

The Ganguyi church is north face and the main building has two layers of stone base brick structure and gray wall. As shown in Figure 4, the plane of the church is a rectangular with 30.94 meters long from north to south and 12.79 meters wide from east to west and 14.6 meters high. There are five square columns at both side of the church which support the middle arch securities roof. These columns divide the interior space into three corridor type. The center hall is higher than the side halls. The center hall has side window and high window to let the light come in. the light is mysterious due to the color glass. The north of the church is the half circular chancel with six sharp coupons high windows covered dome. As shown in Figure 5, the elevation of the church is a typical Gothic style, by the office of the clock tower and two side of gable hall. The wide of the church is 12.79 meters and the tower is 14.6 meters high. The bell tower has three segments. The first layer is composed of beam column stacked unsmooth transparent coupon-type door with lintel stone chrysanthemum carved with peony, plum and grape pattern.

The second layer has three sharp coupons-like long narrow window with banner carved with "Catholic". The wall of the church decorated with continuous cusp securities constitutes the gallery bar. The third layer is a hexagonal tower. The surfaces are decorated with strip-shaped ventilating shutters and bell tower housed inside. The pilasters are decorated with many small spires. The entrance has gable walls symmetry. Each wall has a sharp coupon-like stone false window. The window is carved with dragon and plant style decoration. There is a rose window round the false window carved with lotus pattern with strong local color style.

As shown in Figure 6, the Ganguyi church is a stone base brick structure with thin and high windows. The light through the color window create a brilliant and mysterious atmosphere. The elevation of the church uses a large number of sharp coupons, spire steeple decoration. The church has strong upward movements with delicate and gorgeous carve which achieve a high thin, sublimate and mysterious pathos aesthetics effect.

\subsection{Interior Space Design}

With respect to interior space design, owing to the influence of Chinese and western culture, the interior design combines elements in Chinese traditional culture and religion elements in western countries. In general, the design of interior space conforms to the architectural styles of western culture, while the nuances manifest Chinese traditional culture. We will take Qiao'ergou as the example to expound the interior space design of church architecture in Yan'an area.

The middle hall of interior space is higher than aisle gallery, with its roof ceiling in stone semicircle arch structure. Constructed by a continuous arch, the aisle of both rows are divided into three parts by 12 Collins pillars, with the height of $4.5 \mathrm{~m}$, the interval space of $7.2 \mathrm{~m}$ and the side space of $3.4 \mathrm{~m}$. Each pillar is sculptured 


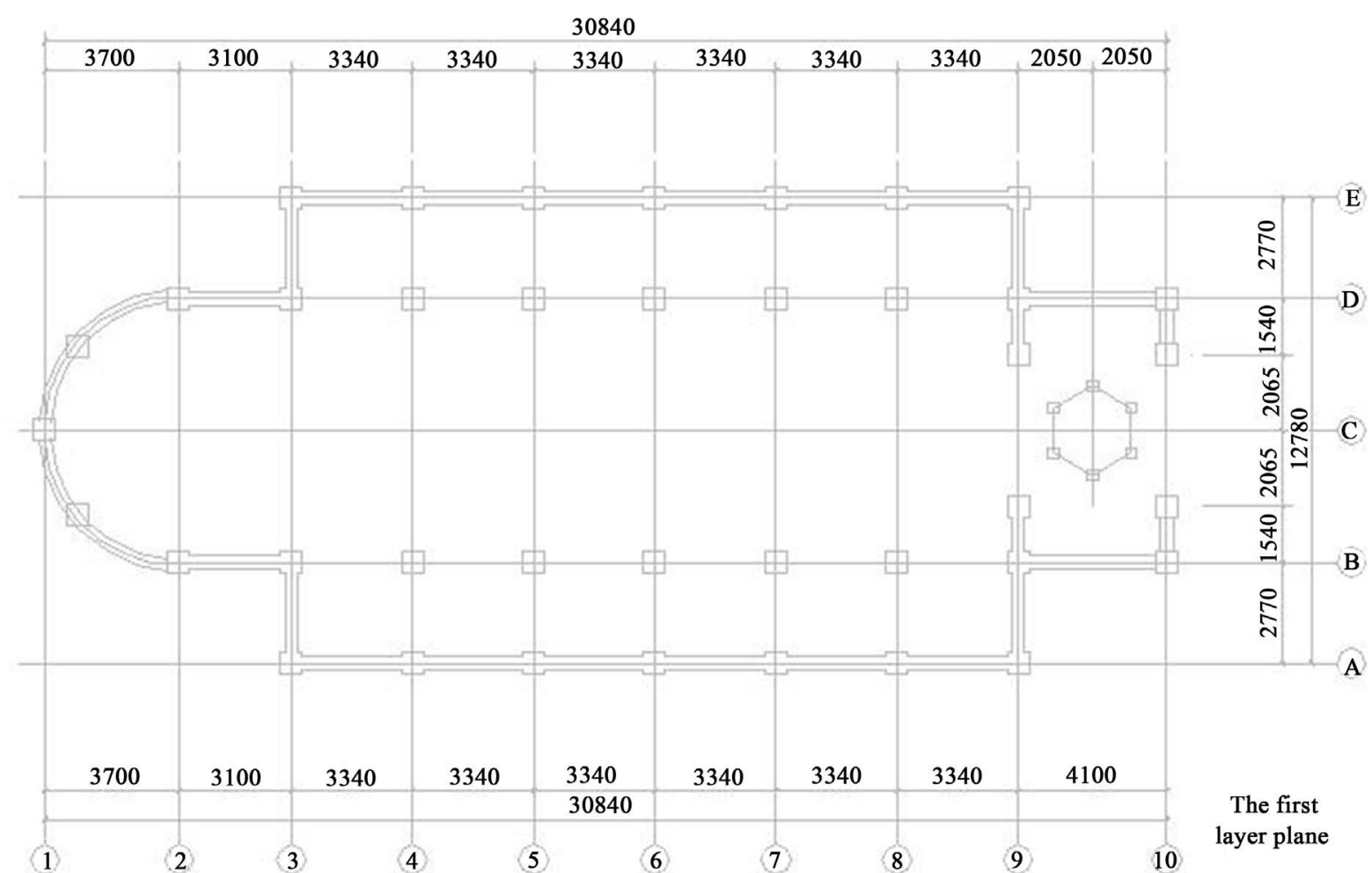

Figure 4. The plane of Ganguyi Church.

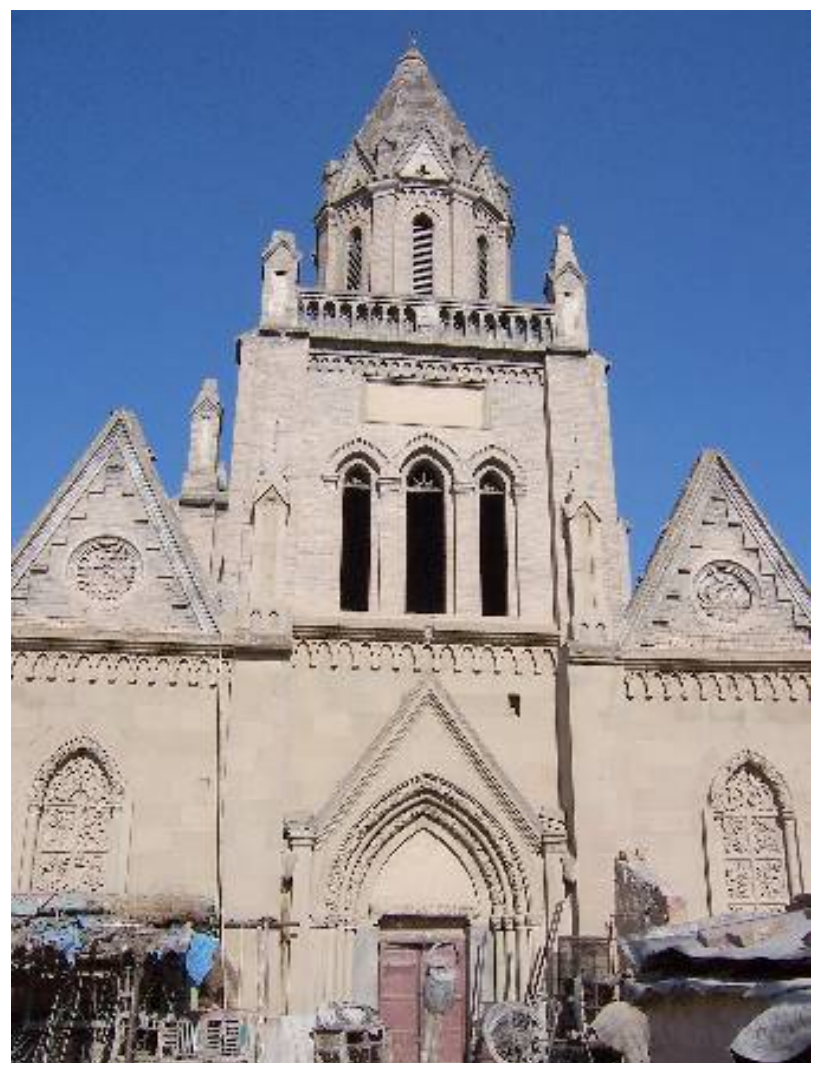

Figure 5. The south facade of the church. 


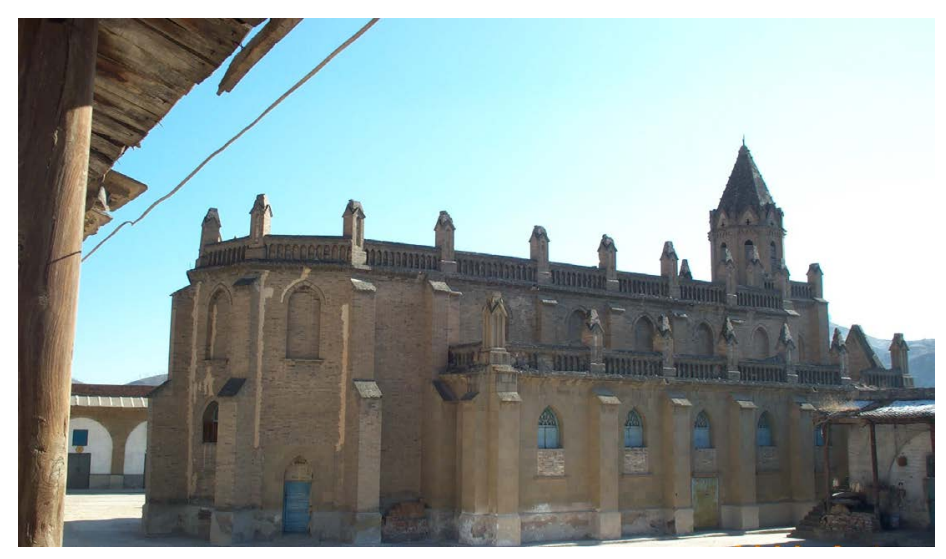

Figure 6. The west facade of the church.

with different Chinese plant types. Due to the use of continuous arch, the interior space appears a kind of mysterious atmosphere. At the northern end of the church, altar is build and decorated with bamboo, plum and lotus, which is different from western churches. Besides, setting steps leads to the altar higher than the room. The wall near to the altar is set with pilaster and beautifully decorated brick niche which has been paved over now.

\subsection{Architecture Landscape}

Situated in the area of the Loess Plateau which owns its special geological landforms, loess characteristics, climatic conditions, native culture and other factors, Yan'an area constitutes the unique traditional settlement after a long history of evolution, named cave. The cave shows strong local tradition cultural characteristic, such as human settlement location, building construction, architectural form and architecture color.

The traditional settlement location of Yan'an area inherits the Chinese traditional Feng-Shui theory which strives to back mountain and face water. The architecture is normally face north and mainly arched with curve which embodies the world view of "circle sky and square earth". The construction material mainly uses the local stone, green brick and loess. The tone of the construction is mainly yellow and grey. The decoration of the construction is mainly brick and stone carve with rough lines. These entire phenomena reflected the loess culture characteristics of broad, rough and thickness.

Modern church in Yan'an area can be divided into western architecture form according to the architecture system. Compared to other western building style church, these modern churches show the traditional regional culture characteristics of Yan'an area. From the site selection view, these churches present the principles of mountain adhere which agree with the local construction site selection principle. From the orientation view of the building, these churches towards are sitting west and head east which agree with the western Christian religious ceremony, while the Yan'an area church are towards south like the cave.

From the architecture form view, the church adopts the western style beam column masonry arch structure. Compared to the cave structure, both of them use the arch curve structure but different from that the western arch structure creates more varied deep space. From the building materials, the church is still use local stone and brick. From the tone of the construction, the church mainly uses yellow and gray and use red and green as supplement. The main tone is consisting with the cave tone while the supplement tone exhibits the auxiliary color of the church. From the decoration of the architecture, the decoration pattern of the church not only use the cross, angel, grape and sheep peculiar pattern, but also use a large number of Yan'an traditional culture, such as auspicious blessing, loyalty, justice and other meaning pattern.

From the above discussion, it can be seen that the modern church in Yan'an area is western-style building. But the church fuses the local building techniques of Yan'an area in building orientation, material, tone and decoration aspects which have both the western culture and local region architecture features. All of these aspects form a unique landscape of the combination of Chinese and western characteristics.

\section{Summary}

The modern church architecture left in Yan'an area is not only the dissemination history record of propagation 
of Christian culture, but also the history record of the communication between the western culture and local traditional culture in Yan'an area. In this paper, we fist analyze the situation of Christianity in Shannxi and we get the conclusion that there are totally 23 churches in the modern Yan'an areas, where the Christian church number is 12 and the Protestant church is 11, respectively. Then we mainly discuss the architectural style, interior space design and architectural landscape of the church architecture in Yan'an area. As for the architectural style, Rome architecture style and Gothic architecture style are representatives of the church architecture in Yan'an area. In regard to interior space design, it generally conforms to the western architectural tradition while it differs in details with Chinese traditional plants, patterns and habitations. Owing to the unique geological landforms, loess characteristics, climatic conditions, native culture and traditional settlement location, the architectural landscape of church architecture in Yan'an area inherits the Chinese traditional theory. Furthermore, these churches present the principles of mountain adherent to the local construction site selection principle and churches in Yan'an area are towards south.

The modern China is a time with strong collision between the western and Chinese culture. The church architecture is the most typical architecture style to represent the western culture. Because of the deep location in mainland, the quality and quantity of architecture in Yan'an area are much less than those in coastal areas and Yangtze River region. Therefore, it is seldom to see the church architecture in Yan'an area.

The modern church architecture is a footprint of the development of Yan'an area. Although it transplants the western culture character sometimes, the church architecture is an important example of the religious history and city culture. We investigate the modern church architecture of Yan'an area under the view of culture inheritance, and provide information for the continued and protection of architecture culture of Yan'an area.

\section{Funding}

Supported by the Fundamental Research Funds for the Central Universities (No. 2452015041). The Doctoral Scientific Research Foundation of Northwest A \& F University (No. 2014BSJJ031).

\section{References}

[1] Yan'an Local Chronicles Compilation Committee (1994) Yan'an Area Chronicles. Shaanxi Press, Xi'an, 698.

[2] Zhuo, X.P. and The Chinese Culture History Journal Editorial Committee (1998) Christian Judaism. Shanghai People's Publishing House, Shanghai, 248.

[3] Zhang, L. and Liu, J.T. (1987) History of Chinese Teaching Plan. Sichuan Social Science Press, Chengdu, 38-45.

[4] Zhang, F.H. (2004) Research and Protection of Modern Architecture in China. Tsinghua University Press, Beijing, 4068.

[5] Institute of World Religions (1991) Chinese Academy of Sciences. Christian Cultural Perspective. Qilu Press, Ji’nan, 287. 